\title{
Risk of extracolonic second primary cancers following a primary colorectal cancer: a systematic review and meta-analysis
}

\author{
Dylan Robertson $^{1} \cdot$ Shu Kay Ng ${ }^{1} \cdot$ Peter D. Baade ${ }^{1,2} \cdot$ Alfred K. Lam $^{1,3,4}$ (D)
}

Accepted: 2 February 2022 / Published online: 12 February 2022

(c) The Author(s) 2022

\begin{abstract}
Purpose The purpose of the study is to assess the global risk of extracolonic secondary primary cancers (SPCs) in patients with colorectal cancer (CRC).

Methods Studies of SPC in patients with CRC were included if they reported the standardised incidence ratio (SIR) for extracolonic SPCs in patients with CRC compared with the general population. Pooled summary estimates were calculated using a random-effects model.

Results A total of 7,716,750 patients with CRC from 13 retrospective cohort studies that reported extracolonic SPC incidence were included. The overall risk of several SPCs was significantly higher in patients with CRC compared with the general population, including cancers of the urinary bladder (pooled SIR 1.19, 95\% confidence interval (CI) 1.06-1.33; $p=0.003$ ), female genital tract $(1.88,1.07-3.31 ; p=0.03)$, kidney $(1.50,1.19-1.89 ; p=0.0007)$, thorax (lung, bronchus and mediastinum) $(1.16,1.01-1.32 ; p=0.03)$, small intestine $(4.26,2.58-7.01 ; p<0.0001)$, stomach $(1.22,1.07-1.39 ; p=0.003)$, and thyroid $(1.40,1.28-1.53 ; p<0.0001)$, as well as melanoma $(1.28,1.01-1.62 ; p=0.04)$. There was also a decreased risk of developing cancer of the gall bladder $(0.75,0.60-0.94 ; p=0.01)$.

Conclusion Patients with CRC had a significantly increased risk of extracolonic SPCs compared with the general population. These findings highlight the need to develop research strategies for the management of second primary cancer in patients with CRC.
\end{abstract}

Keywords Colorectal cancer $\cdot$ Second primary cancer $\cdot$ Multiple malignancies $\cdot$ Risk factors $\cdot$ Population-based study . Meta-analysis

\section{Introduction}

Colorectal cancer (CRC) is the fourth most common cancer type in the world and the third most deadly, accounting for about $10 \%$ of all incident cancers and cancer-related deaths each year [1,2]. Although there have been improvements in the prognosis of patients with CRC due to recent advances

Alfred K. Lam

a.lam@griffith.edu.au

1 School of Medicine and Dentistry, Menzies Health Institute Queensland, Griffith University, Gold Coast, QLD, Australia

2 Cancer Council Queensland, Brisbane, QLD, Australia

3 Pathology Queensland, Gold Coast University Hospital, Gold Coast, QLD, Australia

4 Pathology, School of Medicine and Dentistry, Menzies Health Institute Queensland, Griffith University, Gold Coast Campus, Southport, QLD 4222, Australia in the screening, early detection, and treatment of CRC [3], the disease remains an important health issue worldwide. In addition, there has been an unexplained increase among young people [3-7]. This expanding population of CRC survivors faces long-term health concerns [8], such as the increased risk of developing second primary cancers (SPCs) [1, 9-21]. The reasons for this elevated risk remain unelucidated; however, various hypotheses have been posited in recent years, particularly familial genetic predispositions such as Lynch syndrome [22, 23], similar tumorigenic epigenetic changes in response to environmental exposures, or carcinogens related to tissues originating from the same germ layer [17], as well as specific mutations common to CRC and certain second cancers [24]. While the risk of synchronous and metachronous multiple malignancies of the colorectum have been well documented [20], evidence for the risk of extracolonic SPCs among CRC survivors has been less consistent [9-14, 17, 25, 26]. Around the world, 
CRC has been associated with extracolonic SPCs, including but not limited to malignancies of the urinary bladder $[10,12,13,25,26]$, breast $[11,12,27]$, kidney [10, 12], ovary [11, 12], pancreas [11-13, 25, 26], prostate [11, 12], stomach $[11,13,25,26]$, small intestine [11-13, 25, 26], and endometrium [12]. These mixed findings are indicative of the vast heterogeneity among countries and demonstrate the need to determine these risks to inform strategies for subsequent cancer surveillance following the management of primary CRC. Therefore, we carried out a systematic review and meta-analysis to investigate the risk of extracolonic SPCs in patients with CRC compared with the general population.

\section{Methods}

This systematic review and meta-analysis were done according to pre-specified criteria and followed the Preferred Reporting Items for Systematic Reviews and Meta-Analyses (PRISMA) guidelines for the reporting of meta-analyses.

\section{Data sources and searches}

We searched PubMed, Embase, Scopus, and the Cochrane electronic database for studies published from each database's inception to 27 Dec 2021, assessing the risk of SPCs in patients with CRC, using the following search terms: "colorectal cancer", "bowel cancer", "second cancer", "second primary cancer", "second malignancies", "multiple primary cancer", "multiple primary malignancies", and "multiple primaries".

\section{Inclusion and exclusion criteria}

Articles were eligible for inclusion if they reported the risk of extracolonic SPCs in patients with CRC, in terms of standardised incidence ratio (SIR). We included only studies that reported SIR estimates in our analyses since they provided an indirect method of adjustment for age and gender. No restrictions were applied to age, gender, comorbidities, duration, or location of the study, nor method of reporting cancer diagnoses. Articles without sufficient data, without reported individual extracolonic SPC risk, on second or multiple metachronous CRC, synchronous second or multiple cancers, centred on treatment modalities, and with overlapping populations and time periods were excluded. Only articles published in English were considered. The titles and abstracts of potentially eligible articles according to these eligibility criteria, and any duplicates, were excluded. Full-text articles were retrieved for studies that met the eligibility criteria. At this point, we excluded studies that did not include patients with CRC or did not report the SIR with respective 95\% confidence intervals (CIs).

\section{Data extraction and quality assessment}

Data were extracted from all eligible studies using predefined data extraction form: study characteristics (study design, year of publication, and corresponding author), study setting (location and period), study population characteristics (sample size, age, and gender of the patients), and outcomes (duration of follow-up and cancer incidence per cancer type). Diagnosis and confirmation of CRC and SPCs were done according to the criteria of each study. The corresponding authors of the studies, or the national registry databases used as a data source in the original studies, were consulted for additional information if required. The methodological quality evaluation of each cohort study was based on the Newcastle-Ottawa Scale.

\section{Outcome measures}

The primary outcome measure was the incidence of extracolonic SPCs in patients with CRC, reported as SIRs. The SIR was defined in each study as the number of observed cancers in patients with CRC compared with the number of expected cancers in the general population. Specific details of how the expected number of neoplasms were calculated in each study have been summarised in Supplementary Table 1.

\section{Statistical analyses}

We used random-effects meta-analysis to assess the risk of extracolonic SPCs in patients with CRC. To calculate the pooled SIR of SPCs, we combined the extracted study-specific estimates and corresponding 95\% CIs using the DerSimonian and Laird random-effects model [28]. The Newcastle-Ottawa Scale was used to assess the risk of bias of the included studies [29]. Studies with a rating of 6 or higher were considered high quality. The heterogeneity across studies was assessed using the $I^{2}$ statistic $\left(I^{2} 0-25 \%\right.$, mild heterogeneity; $I^{2} 25-50 \%$ moderate heterogeneity; $I^{2}>50 \%$, large heterogeneity) [19]. We used funnel plots to assess the potential for small-study effects (publication bias). All statistical analyses used RevMan (version 5.4.1. Copenhagen: The Nordic Cochrane Centre, The Cochrane Collaboration). All statistical tests used a two-sided $\alpha$ value of 0.05 for statistical significance.

\section{Results}

\section{Literature search}

Searches returned 2522 records, with an additional 4 records identified through reference lists, of which 2259 were excluded after an initial screening of duplicates, titles, and abstracts. Full texts were retrieved for 170 studies and 
assessed for eligibility (Fig. 1). Thirteen studies published between 1999 and 2021, including 7,716,750 patients $\left(2.01 \times 10^{9}\right.$ person-years) with CRC that reported extracolonic SPCs cancer incidence, were included in the metaanalysis according to our inclusion criteria $[16,18,21,27$, 30-38]. The median Newcastle-Ottawa rating for the studies included was 8 (interquartile range (IQR) (7-8)). The population characteristics and outcomes of the included studies are summarised in Table 1 . The median age of the study populations ranges from 56 to 73 .

\section{Risk of extracolonic SPCs in CRC patients}

We analysed the risk of extracolonic SPCs in patients with CRC among 13 studies reporting SIR (Table 1). The risk of several second primary cancers was significantly higher in patients with CRC compared with the general population's risk of developing respective primary cancers. The risk of subsequent malignancies was greatest in the small intestine (pooled SIR $=4.26(95 \% \mathrm{CI}=2.58-7.01$; $p<0.0001)$ ) from four studies $[18,21,32,33]$; followed by the female genitals $(1.88(1.07-3.31 ; p=0.03))$ from three studies [16, 32, 34]; kidney $(1.50(1.19-1.89 ; p=0.0007))$ from seven studies [16, 18, 21, 32-34, 37]; thyroid (1.40 $(1.28-1.53 ; p<0.0001))$ from three studies $[33,34,36]$; skin (melanoma) $(1.28(1.01-1.62 ; p=0.04))$ from eight studies [16, 18, 21, 30, 32-35]; stomach $1.22((1.07-1.39$; $p=0.003)$ ) from seven studies [16, 18, 21, 27, 32-34]; urinary bladder $(1.19(1.06-1.33 ; p<0.0001))$ from seven studies [16, 18, 21, 32-34, 37]; and lung, bronchi, and mediastinum $(1.16(1.01-1.32 ; p=0.03))$ from seven studies [16, 18, 21, 32-35]; Fig. 2. In contrast, there was a decreased risk of second primary gall bladder cancer (pooled SIR $=0.75 ; 95 \% \mathrm{CI}=0.60-0.94 ; p=0.01$ ) from three studies [21, 33, 38]; Fig. 3). There was no significant difference in the risk of second primary cancers of the prostate, pancreatic, ovaries, oesophagus, upper aerodigestive tract, liver and biliary tract, breast, cervix, uterus, and brain, nor in non-Hodgkin lymphoma, leukaemia, and myeloma $(p>0.05)$. The median follow-up years for each SPC are outlined in Table 2. According to the studies included in our analysis, the median follow-up time for SPCs was 4.2 years.
Fig. 1 Preferred Reporting Items for Systematic Reviews and Meta-Analyses (PRISMA) flowchart

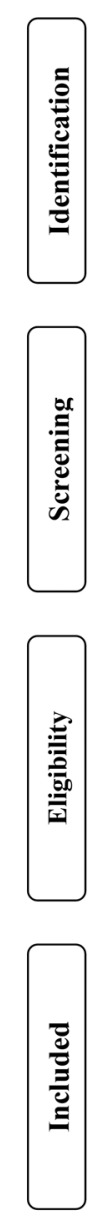

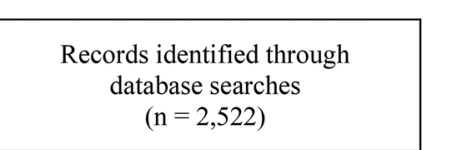
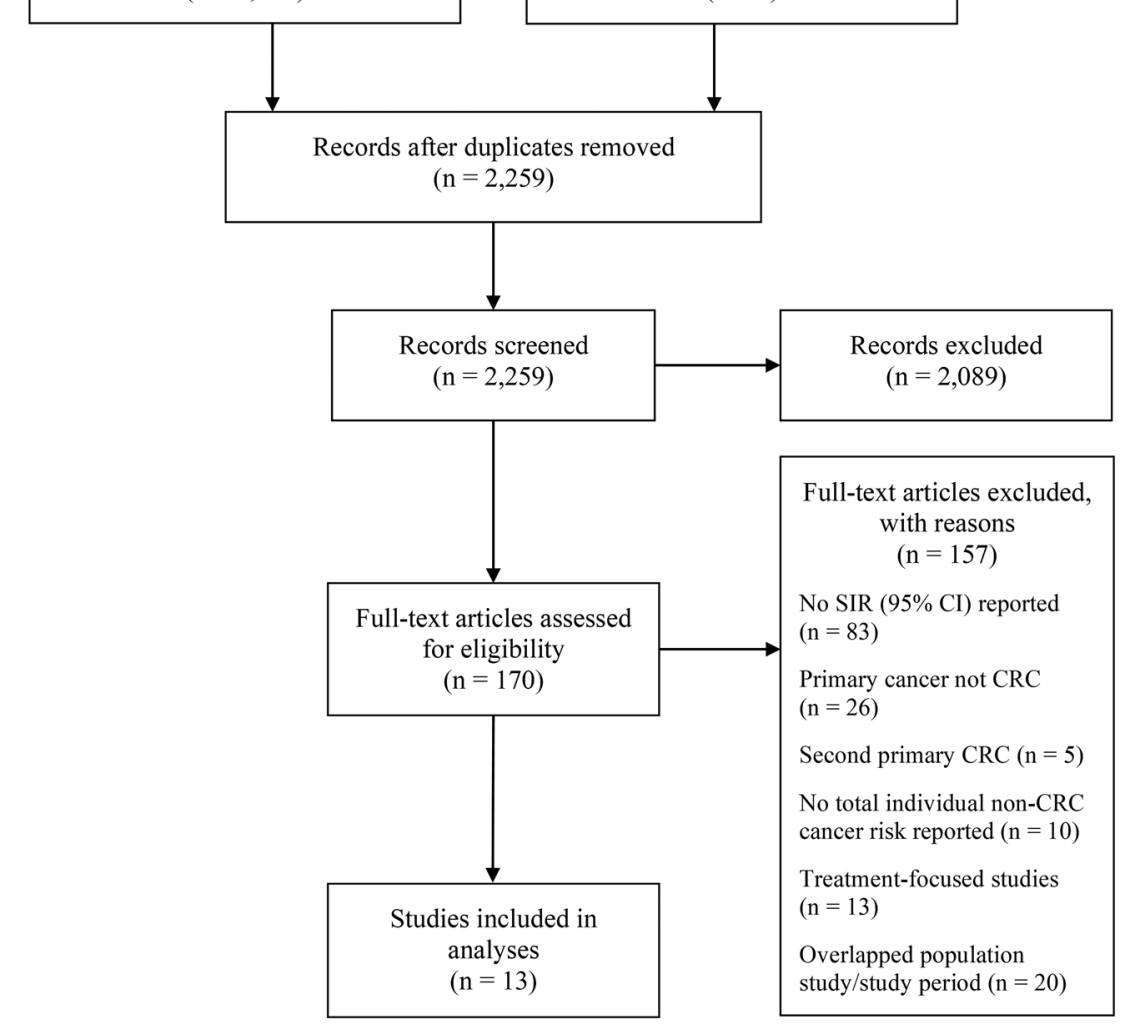


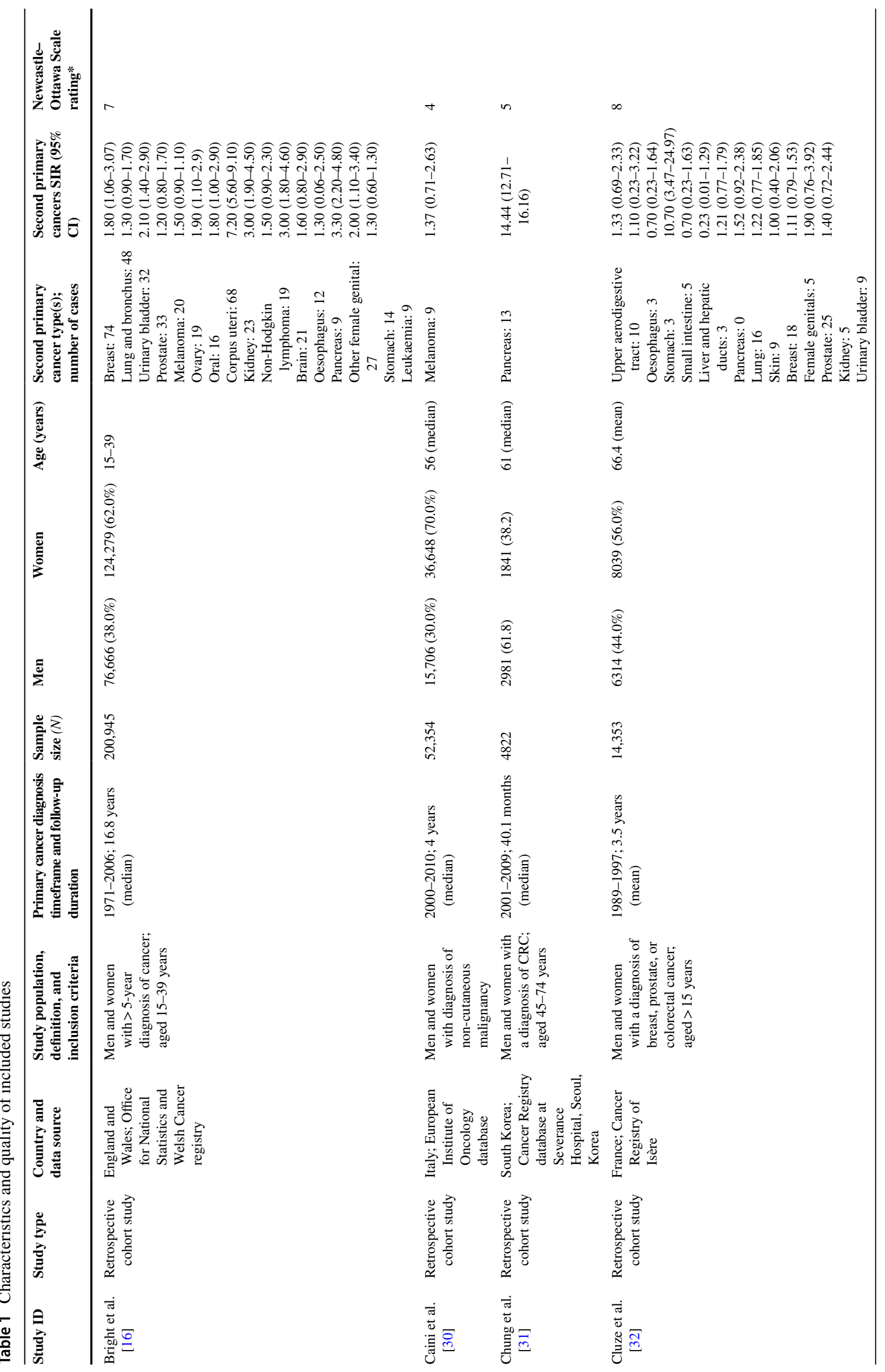




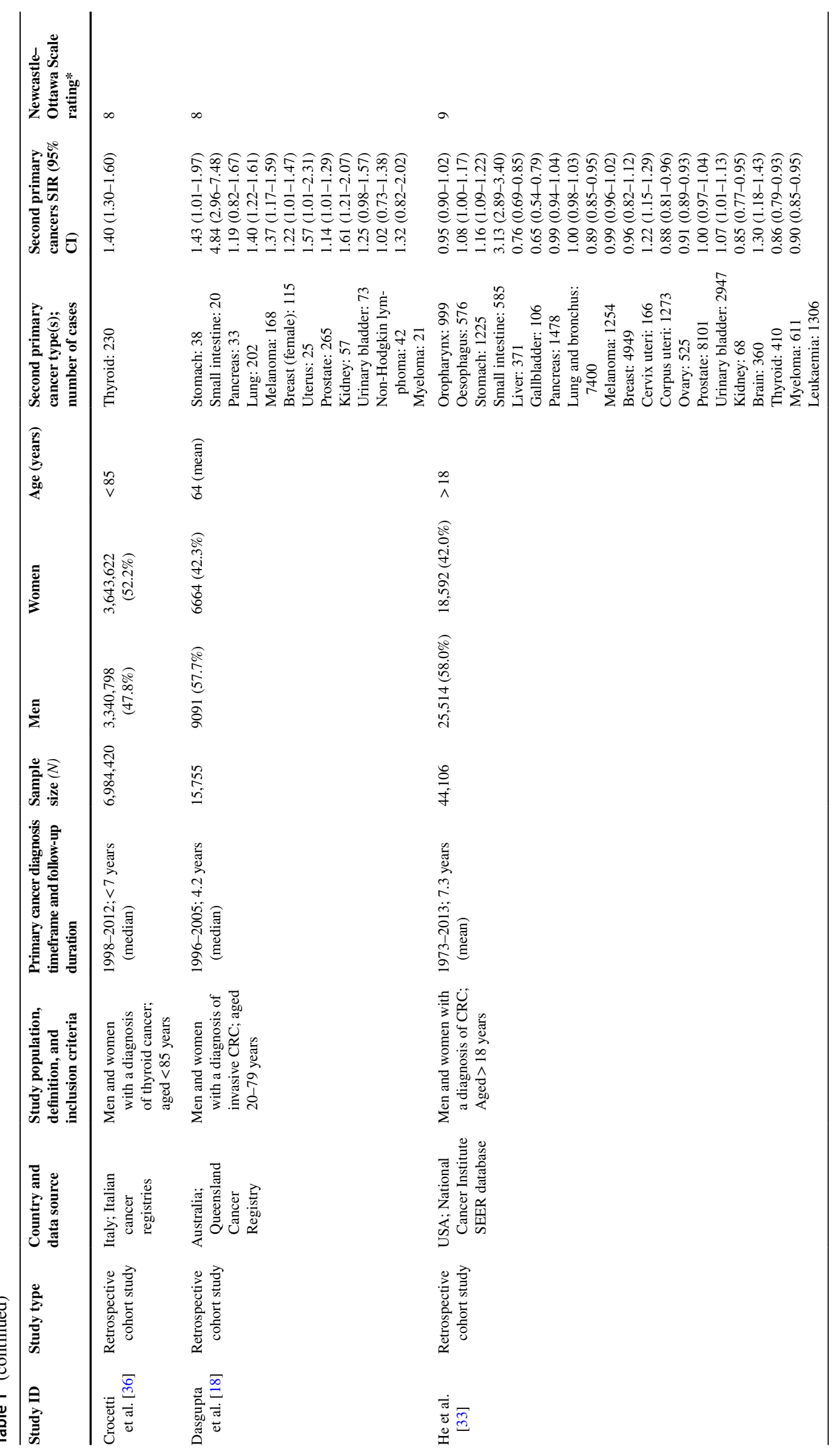




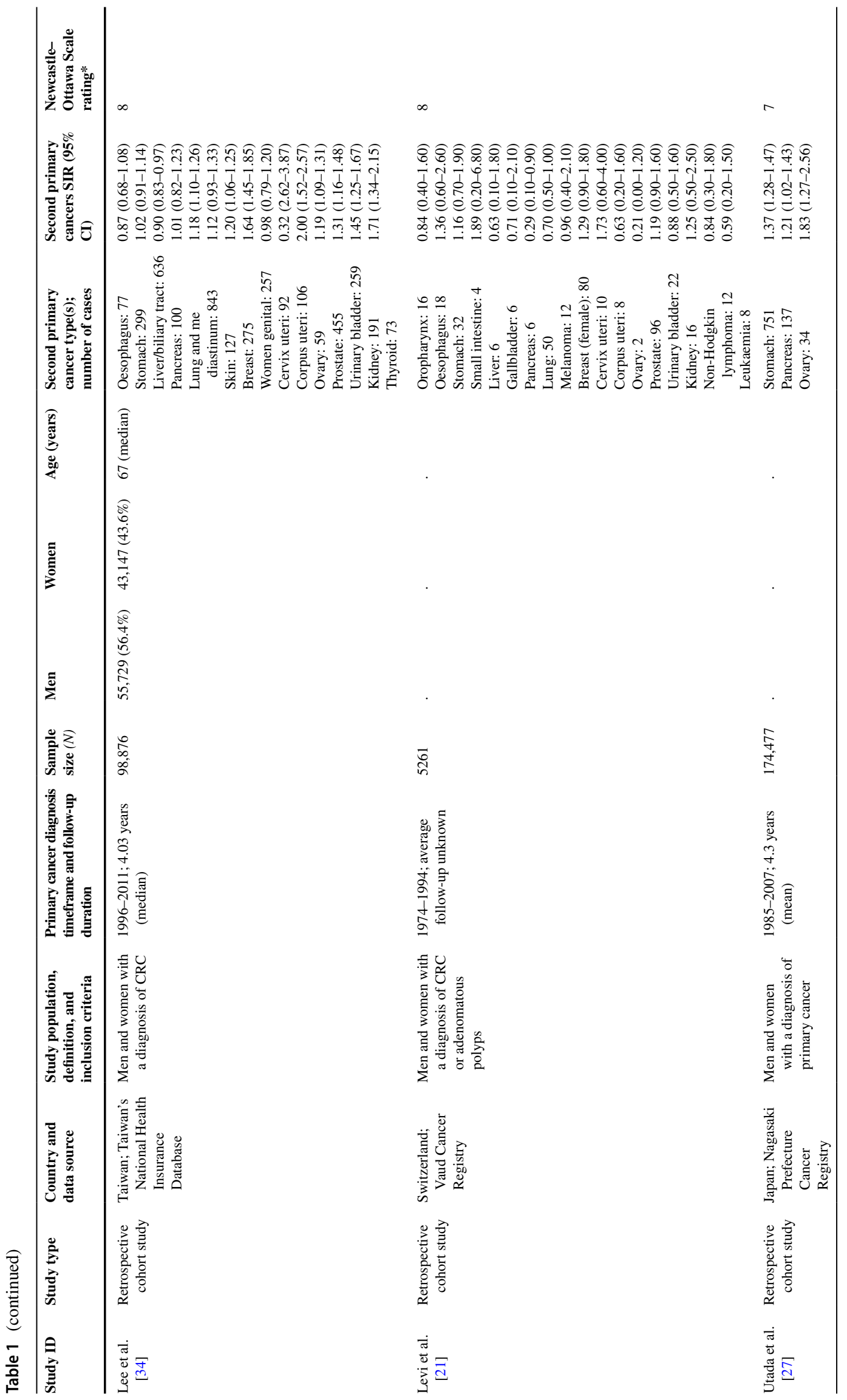




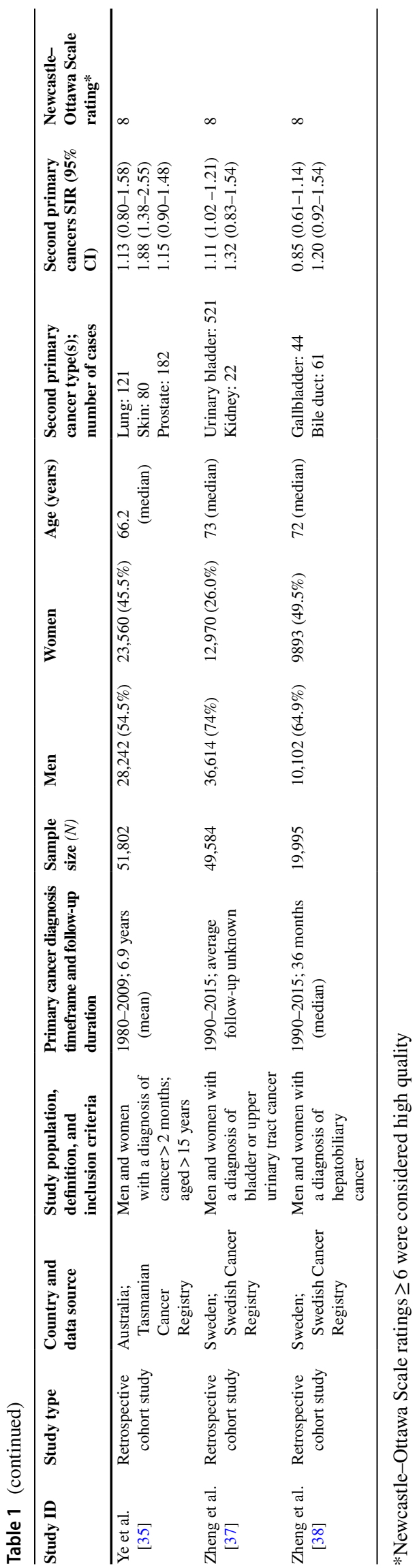

\section{Publication bias}

Heterogeneity was high in studies investigating the risk of urinary bladder, prostate, pancreatic, ovarian, stomach, kidney, lung, small intestine, upper aerodigestive tract, breast, uterine, thyroid, brain, female genital, and liver, hepatic duct, and biliary tract cancers, as well as melanoma, leukaemia, and myeloma. However, visual inspection of funnel plots showed no asymmetry which indicated no publication biases were present (Supplementary Fig. 1).

\section{Discussion}

The findings of this systematic review and meta-analysis suggest that patients with CRC have a significantly higher risk of extracolonic SPCs than the general population, including cancers of the urinary bladder, female genitals, kidney, lung, bronchus and mediastinum, small intestine, stomach, and thyroid, as well as melanoma. The greatest risk was observed for SPC of the small intestine, more than fourfold, compared with the general population, while the increased risk was relatively less for other sites (less than twofold).

Previous studies have reported an increased risk of SPCs following CRC, particularly cancers of the urinary bladder $[10,12]$, kidney $[10,12]$, stomach $[9,10,12]$, and the small intestine [9-12,17], which are consistent with the results of our meta-analysis. Because of these findings, several possible mechanisms have been discussed. For example, some of the risks can be attributed to genetic predisposition, such as in cases of Lynch syndrome (hereditary non-polyposis colorectal cancer familial cancer syndrome), albeit rare [22, 23]. Another hypothesis pertains to the expectation that embryologically related tissues might respond in similar ways to environmental exposures or carcinogens and undergo comparable epigenetic changes conducive to tumourigenesis [17]. Indeed, the small intestine, stomach, urinary bladder, and lung share endoderm-derived epithelia and, therefore, may be linked in this manner. However, this was not supported by our observed decrease in the risk of second primary gall bladder cancer. Alternatively, specific mutations common to CRC and certain second primary malignancies may be responsible for the elevated risk. For instance, $v$-raf murine sarcoma viral oncogene homologue $\mathrm{B} 1$ (BRAF), one of the most frequently mutated protein kinase genes in human cancers, mutations are seen in melanoma, papillary thyroid carcinoma, and CRC [24]. In addition, in the follow-up of CRC, many of these SPCs of high prevalence (including cancers of the urinary bladder, female genitals, kidney, lung, bronchus and mediastinum, small intestine, and stomach) could be detected on the follow-up abdominal 


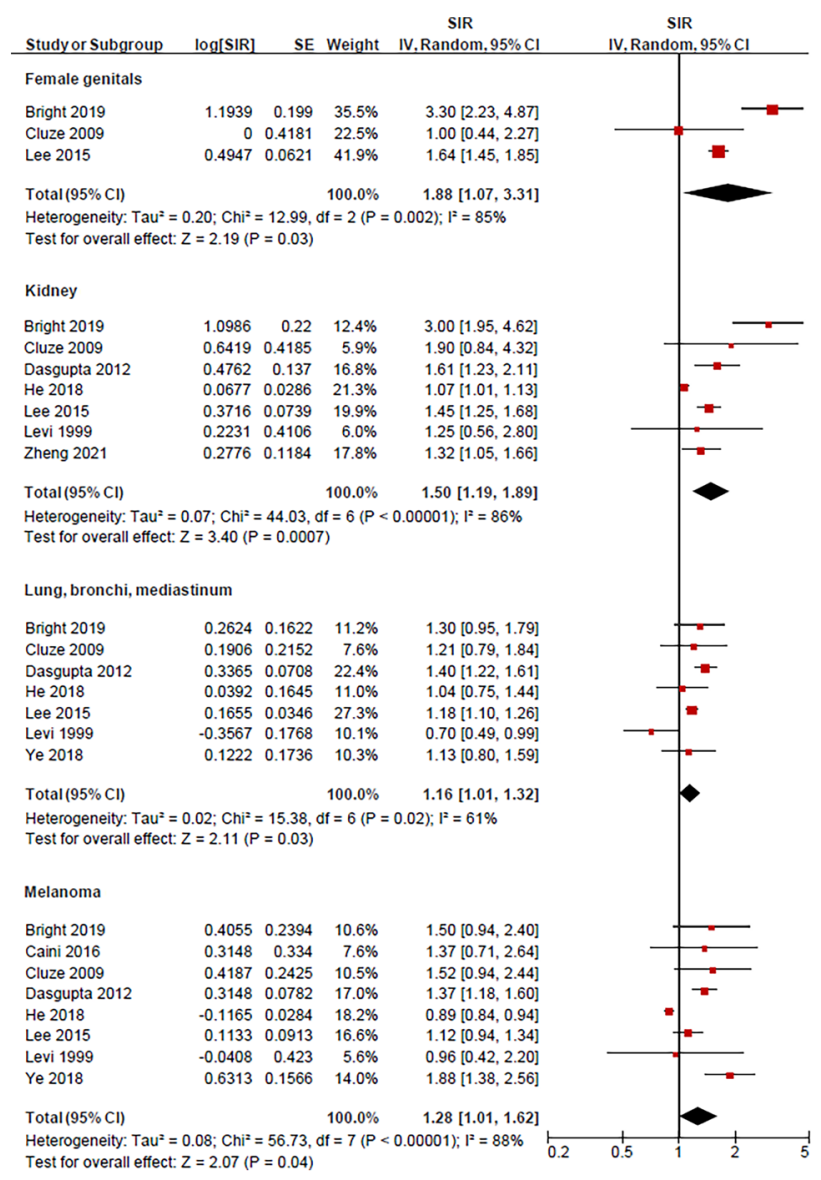

Fig. 2 Second primary cancers with an increased risk following primary colorectal cancer including cancers from female genitals, kidney, thorax (lung, bronchi, and mediastinum), stomach, thyroid, urinary bladder, and small intestine as well as melanoma. The red squares and their sizes represent the effect sizes and weights of the included studies, respectively. The black diamonds and their sizes

and chest computed tomography (CT) scan which may also contribute to higher pick-up rate of these SPCs.

Our study had several limitations. Misclassification of cancers in registry-based investigations may introduce overor underestimation of SPC incidence rates. As we did not include metachronous CRC in our analysis, differentiating between SPCs and local recurrences was not an issue. Additionally, most studies reported attempts to prevent the inclusion of synchronous cancers by excluding subsequent cancers diagnosed within 2 months of the index CRC. There may have been some level of misclassification with respect to tumours arising in discrete sites, namely the lungs, bronchi, and mediastinum; upper aerodigestive tract; female genitals; and the liver, hepatic ducts, and biliary system. As such, we only pooled second cancers of discrete sites where explicitly consistent between individual studies for the robustness of our interpretations.
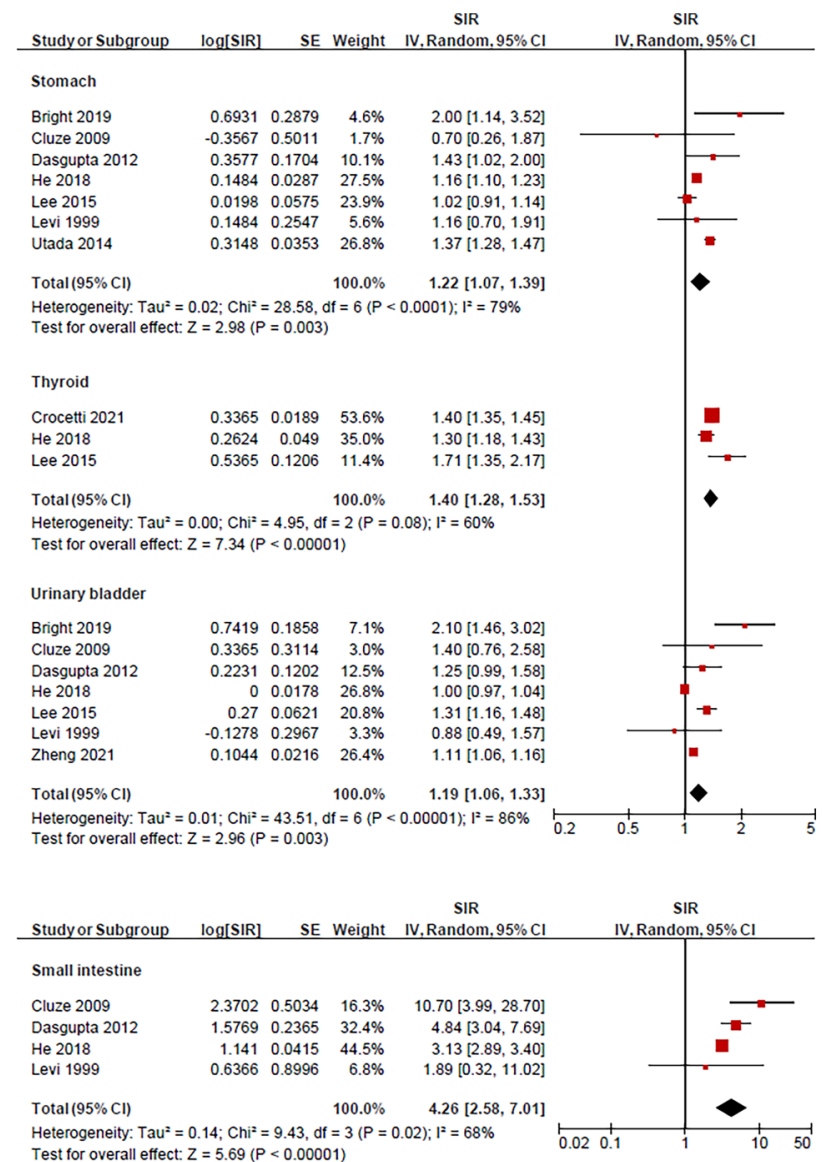

Test for overall effect: $Z=5.69(P<0.00001)$

represent the pooled effect size and their 95\% confidence intervals, respectively. The centre line of no effect runs through the value 1 . Points to the right of the centre line $(>1)$ indicate an increased risk, whereas points to the left of the centre line $(<1)$ indicate a decreased risk

Although we anticipated and attempted to address heterogeneity in our planned analysis, it remained substantial for most pooled second cancers. This is likely due to epidemiological differences between studies, such as follow-up, the periods of time covered, changes in specific cancer demographics across time, varying selection criteria, and temporospatial differences in treatment modalities. Comparably moderate-to-high levels of heterogeneity have been previously observed and discussed in other meta-analyses on SPC [39, 40]. The heterogeneity in these meta-analyses can be largely attributed to differences in the magnitude of risk observed between studies. Ultimately, while we cannot be certain of the true magnitude of in the risk reported in the present study, our results are indicative of an increase in risk of specific second primary malignancies leading to further foci of research in the field. 


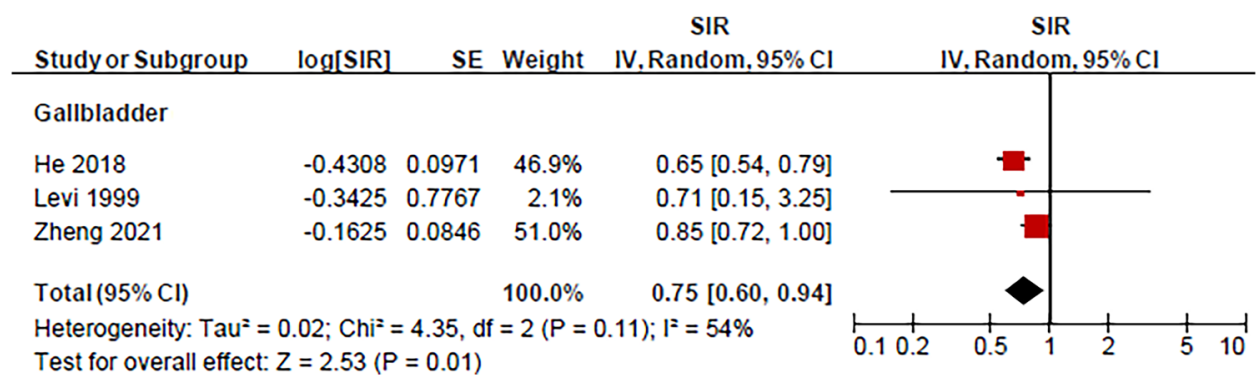

Fig. 3 Second primary cancers with a decreased risk of following primary colorectal cancer: gall bladder cancer. The red squares and their sizes represent the effect sizes and weights of the included studies, respectively. The black diamond and its size represent the pooled

There is lack of data to clearly document the effect of occurrence of SPC in the overall survival of patients with SPC. The survival of these patients is likely to be depending on the nature of the primary CRC and the SPC. If the $\mathrm{CRC}$ is of advanced stages and with residual cancer after resection as well as with mutation not amendable to target therapy, it is likely the survival is dismal and the impact of SPC on the survival is not apparent. On the

Table 2 Median follow-up periods for the second primary cancers included in the meta-analysis

\begin{tabular}{ll}
\hline Second cancer & $\begin{array}{l}\text { Median } \\
\text { follow-up } \\
\text { years (IQR) }\end{array}$ \\
\hline Urinary bladder & $4.2(3.8-12.1)$ \\
Brain & 12.1 \\
Breast & $4.2(3.8-12.1)$ \\
Cervix & 5.7 \\
Female genital & $4.0(3.5-16.8)$ \\
Gallbladder & 7.3 \\
Kidney & $4.2(3.8-12.1$ \\
Leukaemia & 12.1 \\
Liver, hepatic duct, and biliary & $4.0(3.5-7.3)$ \\
Lung, bronchus, and mediastinum & $4.2(3.8-12.1)$ \\
Melanoma & $4.1(3.9-9.7)$ \\
Myeloma & 5.8 \\
Non-Hodgkin lymphoma & 10.5 \\
Oesophagus & $5.7(3.6-14.4)$ \\
Ovary & $7.3(4.0-16.8)$ \\
Pancreas & $4.1(3.5-9.7)$ \\
Prostate & $4.2(3.8-12.1)$ \\
Small intestine & $4.2(3.5-7.3)$ \\
Stomach & $4.2(3.8-12.1$ \\
Thyroid & $7.0(4.0-7.3)$ \\
Upper aerodigestive tract & $7.3(3.5-16.8)$ \\
Uterus & $4.2(3.8-12.1)$ \\
\hline &
\end{tabular}

effect size and its $95 \%$ confidence intervals, respectively. The centre line of no effect runs through the value 1 . Points to the right of the centre line $(>1)$ indicate an increased risk, whereas points to the left of the centre line $(<1)$ indicate a decreased risk

other hand, if the CPC is of early stages and after curative resection, the survival of the patients with CRC is obviously affected and likely depend on the SPCs with high patients' mortality and morbidity such as cancers of the thorax (lung, bronchus, and mediastinum) and melanoma [41, 42]. There are also SPCs such as from the urinary bladder, kidney, female genitals, small intestine, and stomach of similar diverse biological aggressiveness as CRC which will have impact of the survival on the patients. The only exception is in patients with SPC of thyroid cancer with is of increasing incidence worldwide. Thyroid cancer is mostly clinically indolent but could contribute to long-term morbidity of the patients with possibility of local recurrence, de-differentiation to clinical aggressive histological type, and thyroxine replacement therapy [43, 44].

In most clinical centres, the management of patients with CRC will be discussed in multidisciplinary team meeting and follow-up with standard protocols (such as radiology and endoscopic examinations) according to the prognostic parameters as well as personalised medical needs (such as comorbidity). Majority of the SPCs of relative higher prevalence could be detected by this means. Thus, awareness of the possibility of SPCs and adherence to protocols of follow-up of patients with CRC is important for best clinical practice. Nevertheless, we need more investigations to look at the length of intervals between CRC and SPCs. With the acknowledgement that the median follow-up time for SPCs from the studies included in our analysis was 4.2 years, it may be in some cases that SPCs may occur after the standard follow-up time for patients with CRC. Education on the patient and general practitioner of the issue should be of value to this group of patients. It is also important to have prospective clinical studies to address to the comorbidity issues and survival impacts in these patients. 


\section{Conclusion}

The findings of this systematic review and meta-analysis suggest that patients with CRC have an increased risk of extracolonic SPCs compared with the general population, including cancers of the urinary bladder, female genitals, kidney, lung, bronchus and mediastinum, small intestine, stomach, and thyroid, as well as melanoma. Future studies monitoring SPC risk in patients with CRC are warranted as there is a need to develop surveillance and management strategies to decrease the burden of subsequent malignancies within this expanding population.

Supplementary information The online version contains supplementary material available at https://doi.org/10.1007/s00384-022-04105-x.

Author contribution Dylan Robertson: writing-original draft, formal analysis, conceptualisation, methodology, investigations, resources, writing-review and editing; Alfred K Lam, Shu K Ng, and Peter D Baade contributed equally to this work: conceptualisation, writingreview and editing. All authors approved the final manuscript.

Funding Open Access funding enabled and organized by CAUL and its Member Institutions.

\section{Declarations}

Conflict of interest The authors declare no competing interests.

Open Access This article is licensed under a Creative Commons Attribution 4.0 International License, which permits use, sharing, adaptation, distribution and reproduction in any medium or format, as long as you give appropriate credit to the original author(s) and the source, provide a link to the Creative Commons licence, and indicate if changes were made. The images or other third party material in this article are included in the article's Creative Commons licence, unless indicated otherwise in a credit line to the material. If material is not included in the article's Creative Commons licence and your intended use is not permitted by statutory regulation or exceeds the permitted use, you will need to obtain permission directly from the copyright holder. To view a copy of this licence, visit http://creativecommons.org/licenses/by/4.0/.

\section{References}

1. Dekker E, Tanis PJ, Vleugels JLA, Kasi PM, Wallace MB (2019) Colorectal cancer. Lancet 394:1467-1480. https://doi. org/10.1016/S0140-6736(19)32319-0

2. Bray F, Ferlay J, Soerjomataram I, Siegel RL, Torre LA, Jemal A (2018) Global cancer statistics 2018: GLOBOCAN estimates of incidence and mortality worldwide for 36 cancers in 185 countries. CA Cancer J Clin 68:394-424. https://doi.org/10. 3322/caac. 21492

3. Araghi M, Soerjomataram I, Bardot A, Ferlay J, Cabasag CJ, Morrison DS et al (2019) Changes in colorectal cancer incidence in seven high-income countries: a population-based study. Lancet Gastroenterol Hepatol 4:511-518. https://doi.org/10. 1016/s2468-1253(19)30147-5
4. Loomans-Kropp HA, Umar A (2019) Increasing incidence of colorectal cancer in young adults. J Cancer Epidemiol 2019:9841295. https://doi.org/10.1155/2F2019/2F9841295

5. Vuik FE, Nieuwenburg SA, Bardou M, Lansdorp-Vogelaar I, Dinis-Ribeiro M, Bento MJ et al (2019) Increasing incidence of colorectal cancer in young adults in Europe over the last 25 years. Gut 68:1820-1826. https://doi.org/10.1136/ gutjnl-2018-317592

6. Kasi PM, Shahjehan F, Cochuyt JJ, Li Z, Colibaseanu DT, Merchea A (2019) Rising proportion of young individuals with rectal and colon cancer. Clin Colorectal Cancer 18:e87-e95. https://doi.org/10.1016/j.clcc.2018.10.002

7. Mauri G, Sartore-Bianchi A, Russo AG, Marsoni S, Bardelli A, Siena $S$ (2019) Early-onset colorectal cancer in young individuals. Mol Oncol 13:109-131. https://doi.org/10.1002/1878-0261.12417

8. Miller KD, Nogueira L, Mariotto AB, Rowland JH, Yabroff KR, Alfano CM et al (2019) Cancer treatment and survivorship statistics, 2019. CA Cancer J Clin 69:363-385. https://doi.org/10. 3322/caac. 21565

9. Ahmed F, Goodman MT, Kosary C, Ruiz B, Wu XC, Chen VW et al (2006) Excess risk of subsequent primary cancers among colorectal carcinoma survivors, 1975-2001. Cancer 107:11621171. https://doi.org/10.1002/cncr.22013

10. Enblad P, Adami HO, Glimelius B, Krusemo U, Påhlman L (1990) The risk of subsequent primary malignant diseases after cancers of the colon and rectum. A nationwide cohort study Cancer 65:2091-2100. https://doi.org/10.1002/1097-0142(19900501) 65:9/3C2091::aid-cncr2820650934/3E3.0.co;2-m

11. McCredie M, Macfarlane GJ, Bell J, Coates M (1997) Second primary cancers after cancers of the colon and rectum in New South Wales, Australia, 1972-1991. Cancer Epidemiol Biomarkers Prev 6:155-160

12. Hemminki K, Li X, Dong C (2001) Second primary cancers after sporadic and familial colorectal cancer. Cancer Epidemiol Biomarkers Prev 10:793-798

13. Evans HS, Møller H, Robinson D, Lewis CM, Bell CM, Hodgson SV (2002) The risk of subsequent primary cancers after colorectal cancer in southeast England. Gut 50:647-652. https://doi.org/10. 1136/2Fgut.50.5.647

14. Ringland CL, Arkenau HT, O'Connell DL, Ward RL (2010) Second primary colorectal cancers (SPCRCs): experiences from a large Australian Cancer Registry. Ann Oncol 21:92-97. https:// doi.org/10.1093/annonc/mdp288

15. Guan X, Jin Y, Chen Y, Jiang Z, Liu Z, Zhao Z et al (2015) The incidence characteristics of second primary malignancy after diagnosis of primary colon and rectal cancer: a population based study. PLoS ONE 10:e0143067. https://doi.org/10.1371/journal. pone. 0143067

16. Bright CJ, Reulen RC, Winter DL, Stark DP, McCabe MG, Edgar AB et al (2019) Risk of subsequent primary neoplasms in survivors of adolescent and young adult cancer (Teenage and Young Adult Cancer Survivor Study): a population-based, cohort study. Lancet Oncol 20:531-545. https://doi.org/10.1016/S14702045(18)30903-3

17. Phipps AI, Chan AT, Ogino S (2013) Anatomic subsite of primary colorectal cancer and subsequent risk and distribution of second cancers. Cancer 119:3140-3147. https://doi.org/10.1002/cncr.28076

18. Dasgupta P, Youlden DR, Baade PD (2012) Multiple primary cancers among colorectal cancer survivors in Queensland, Australia, 1996-2007. Cancer Causes Control 23:1387-1398. https://doi. org/10.1007/s10552-012-9990-1

19. Higgins JP, Thompson SG, Deeks JJ, Altman DG (2003) Measuring inconsistency in meta-analyses. BMJ 327:557-560. https:// doi.org/10.1136/bmj.327.7414.557 
20. Lam AK-Y, Gopalan V, Carmichael R, Buettner PG, Leung M, Smith R et al (2012) Metachronous carcinomas in colorectum and its clinicopathological significance. Internatl J Colorectal Dis 27:1303-1310. https://doi.org/10.3748/2Fwjg.v20.i22.6815

21. Levi F, Randimbison L, La Vecchia C, Te V-C, Franceschi S (1999) Cancer risk following polyps or cancer of the large bowel in Vaud. Switzerland Int J Cancer 80:634-635. https://doi.org/10.1002/(sici) 1097-0215(19990209)80:4/3C634::aid-ijc26/3E3.0.co;2-y

22. Lynch HT, Lynch PM, Lanspa SJ, Snyder CL, Lynch JF, Boland CR (2009) Review of the Lynch syndrome: history, molecular genetics, screening, differential diagnosis, and medicolegal ramifications. Clin Genet 76:1-18. https://doi.org/10.1111/2Fj.13990004.2009.01230.x

23. Win AK, Lindor NM, Young JP, Macrae FA, Young GP, Williamson E et al (2012) Risks of primary extracolonic cancers following colorectal cancer in Lynch syndrome. J Natl Cancer Inst 104:1363-1372. https://doi.org/10.1093/jnci/djs351

24. Pakneshan S, Salajegheh A, Smith RA, Lam AK-Y (2013) Clinicopathological relevance of BRAF mutations in human cancer. Pathology 45:346-356. https://doi.org/10.1097/pat.0b013e328360b61d

25. Heard A, Roder D, Luke C (2005) Multiple primary cancers of separate organ sites: implications for research and cancer control (Australia). Cancer Causes Control 16:475-481. https:// doi.org/10.1007/s 10552-004-8023-0

26. Liang YH, Shao YY, Chen HM, Lai CL, Lin ZZ, Kuo RN et al (2015) Young patients with colorectal cancer have increased risk of second primary cancers. Jpn J Clin Oncol 45:1029-1035. https://doi.org/10.1093/jjco/hyv137

27. Utada M, Ohno Y, Hori M, Soda M (2014) Incidence of multiple primary cancers and interval between first and second primary cancers. Cancer Sci 105:890-896. https://doi.org/10.1111/cas. 12433

28. DerSimonian R, Laird N (1986) Meta-analysis in clinical trials. Control Clin Trials 7:177-188. https://doi.org/10.1016/01972456(86)90046-2

29. Wells GA, Shea B, O'Connell Da, Peterson J, Welch V, Losos $\mathrm{M}$ et al (2011) The Newcastle-Ottawa Scale (NOS) for assessing the quality of nonrandomised studies in meta-analyses. http:// www.ohri.ca/programs/clinical_epidemiology/oxford.asp. Available from: URL: http://www.ohri.ca/programs/clinical_ epidemiology/oxford.asp

30. Caini S, Radice D, Tosti G, Spadola G, Cocorocchio E, Ferrucci PF et al (2016) Risk of second primary malignancies among 1537 melanoma patients and risk of second primary melanoma among 52354 cancer patients in Northern Italy. J Eur Acad Dermatol Venereol 30:1491-1496. https://doi.org/10.1111/jdv.13645

31. Chung JW, Chung MJ, Bang S, Park SW, Song SY, Chung JB et al (2017) Assessment of the risk of colorectal cancer survivors developing a second primary pancreatic cancer. Gut Liver 11:728-732. https://doi.org/10.5009/2Fgnl16526

32. Cluze C, Delafosse P, Seigneurin A, Colonna M (2009) Incidence of second cancer within 5 years of diagnosis of a breast, prostate or colorectal cancer: a population-based study. Eur J Cancer Prev 18:343-348. https://doi.org/10.1097/cej.0b013e32832abd76
33. He X, Wu W, Ding Y, Li Y, Si J, Sun L (2018) Excessive risk of second primary cancers in young-onset colorectal cancer survivors. Cancer Med 7:1201-1210. https://doi.org/10.1002/cam4.1437

34. Lee YT, Liu CJ, Hu YW, Teng CJ, Tzeng CH, Yeh CM et al (2015) Incidence of second primary malignancies following colorectal cancer: a distinct pattern of occurrence between colon and rectal cancers and association of co-morbidity with second primary malignancies in a population-based cohort of 98,876 patients in Taiwan. Medicine 94:e1079. https://doi.org/10.1097/ 2FMD.0000000000001079

35. Ye Y, Otahal P, Wills KE, Neil AL, Venn AJ (2018) Temporal trends in the risk of second primary cancers among survivors of adult-onset cancers, 1980 through 2013: An Australian populationbased study. Cancer 124:1808-1818. https://doi.org/10.1002/cncr. 31247

36. Crocetti E, Mattioli V, Buzzoni C, Franceschi S, Serraino D, Vaccarella $S$ et al (2021) Risk of thyroid as a first or second primary cancer. A population-based study in Italy, 1998-2012. Cancer Med 10(19):6855-67. https://doi.org/10.1002/cam4.4193

37. Zheng G, Sundquist K, Sundquist J, Försti A, Hemminki O, Hemminki $\mathrm{K}$ (2021) Bladder and upper urinary tract cancers as first and second primary cancers. Cancer Rep. https://doi.org/10.1002/cnr2.1406

38. Zheng G, Sundquist K, Sundquist J, Chen T, Försti A, Hemminki A et al (2021) Second primary cancers after liver, gallbladder and bile duct cancers, and these cancers as second primary cancers. Clin Epidemiol 13:683-691. https://doi.org/10.2147/CLEP.S318737

39. Grantzau T, Overgaard J (2016) Risk of second non-breast cancer among patients treated with and without postoperative radiotherapy for primary breast cancer: a systematic review and metaanalysis of population-based studies including 522,739 patients. Radiother Oncol 121:402-413. https://doi.org/10.1016/j.radonc. 2016.08.017

40. Gilbert DC, Wakeham K, Langley RE, Vale CL (2019) Increased risk of second cancers at sites associated with HPV after a prior HPVassociated malignancy, a systematic review and meta-analysis. Br J Cancer 120:256-268. https://doi.org/10.1038/s41416-018-0273-9

41. Ortega-Ortega M, Hanly P, Pearce A, Soerjomataram I, Sharp L (2022) Paid and unpaid productivity losses due to premature mortality from cancer in Europe in 2018. Int J Cancer 150:580-593. https://doi.org/10.1002/ijc.33826

42. Abe I, Lam AK (2021) Anaplastic thyroid carcinoma: Updates on WHO classification, clinicopathological features and staging. Histol Histopathol 36:239-248. https://doi.org/10.14670/HH-18-277

43. Lam AK (2020) Squamous cell carcinoma of thyroid: a unique type of cancer in World Health Organization Classification. Endocr Relat Cancer 27:R177-R192. https://doi.org/10.1530/ ERC-20-0045

44. Lam AK, Lo CY, Lam KS (2005) Papillary carcinoma of thyroid: A 30-yr clinicopathological review of the histological variants. Endocr Pathol 16:323-330. https://doi.org/10.1385/ep:16:4:323

Publisher's Note Springer Nature remains neutral with regard to jurisdictional claims in published maps and institutional affiliations. 